\title{
Peritonite Esclerosante Encapsulante Relacionado A Diálise Peritoneal : Relato De Caso
}

\author{
Rocca, R.; Silva, E.M.; Accorsi, B.F.; Uliano, G.L.; Silva, F.K.D.; Kubiak, M.; \\ Apresentador: Renata Rocca
}

\section{Resumo}

Introdução: A utilização da cavidade peritoneal como opção de tratamento para doentes renais crônicos predispõe a alterações na função e estrutura da membrana peritoneal e apesar de fatores potencialmente modificadores, como a diálise peritoneal(DP), na grande maioria dos casos observa-se alterações mínimas,mas variadas. A peritonite esclerosante encapsulante (PEE) é uma complicação rara nesse tipo de tratamento, com uma incidência de menos de $1 \%$ dos pacientes em diálise peritoneal. Relato de Caso: Paciente J.C.V, masculino, 62 anos, branco, procedente de Arroio do Tigre, Rio Grande do Sul, hipertenso, diabético, vasculopata,em diálise peritonel há 4 anos por nefropatia diabética e história de 5 episódios de peritonite espontânea bactéria(PEB). Paciente chega para atendimento apresentando vômitos fecalóides há duas semanas associados a distensão e dor abdominal. Realizado tomografia computadorizada abdominal que evidenciou alças intestinais dilatadas, níveis hidroaereos. Não houve isolamento de germe em aspirado de líquido abdominal. Não houve resposta a tratamento conservador, por diagnóstico presuntivo de suboclusão intestinal e nova PEB , paciente foi então submetido a laparotomia exploradora,na qual se observou calcificação extensa e espessamento de peritoneo compatíveis com peritonite esclerosante encapsulante. Neste procedimento foi retirado o cateter peritoneal e optado por utilizar no pós-operatório NPT e jejum, devido impossibilidade de se desfazer qualquer aderência. Após procedimento, foi realizado pulsoterapia com corticóide por 3 dias e posteriormente substituído por tamoxifeno, medicação esta também indicado no tratamento de tal entidade, em função de perfil glicemico do paciente. Discussão: A esclerose peritoneal é um processo no qual o peritoneo é transformado em tecido fibroso. A fisiopatologia da PEE ainda não é explicada, mas a exposição contínua a solução não fisiológica pode estar relacionada. O diagnóstico é feito por achados clínicos e radiológicos. Quanto ao tratamento, vê- se resposta favorável ao uso de corticóides e tamoxifeno, nos casos mais graves pode-se optar por tratamento cirúrgico. A PEE é uma entidade rara na diálise peritoneal,no entanto apresenta alta mortalidade. Assim, deve ser suspeitada em pacientes em DP que apresentem sintomas de suboclusão intestinal.

\section{Referência:}

Rocca, R.; Silva, E.M.; Accorsi, B.F.; Uliano, G.L.; Silva, F.K.D.; Kubiak, M.;. Peritonite Esclerosante Encapsulante Relacionado A Diálise Peritoneal : Relato De Caso. In: II Congresso Brasileiro de Medicina Hospitalar - II CBMH [= Blucher Medical Proceedings, vol.1, num.5] São Paulo: Editora Blucher, 2014. p.102

DOI 10.5151/medpro-II-cbmh-102 